ORIGINAL RESEARCH

\title{
The Hawkesbury Canoe Classic: Musculoskeletal Injury Surveillance and Risk Factors Associated With Marathon Paddling
}

\author{
David Abraham, BSc (Med), MBBS; Nicholas Stepkovitch, BAppScPhys, MMPA \\ From Nepean Specialist Sports Medicine, Kingswood, New South Wales, Australia (Dr Abraham); and Sports, Spinal and Rehabilitation \\ Solutions, Hornsby, New South Wales, Australia (Mr Stepkovitch).
}

\begin{abstract}
Objective.-The aim of this study was to assess the incidence and risk factors for musculoskeletal injury associated with marathon paddling.

Methods.-A prospective observational cohort study was conducted during the 2006 Hawkesbury Canoe Classic (HCC), an annual 111-km paddling race in Sydney, Australia. Before the race, a written questionnaire was distributed to competitors to gather information regarding their age, gender, type of craft they were competing in, paddling experience, HCC experience, training distances, and preceding injuries. The paddler's average race speed was also used for analysis. Injuries were recorded throughout the race. Logistic regression analysis was used to identify if any of the variables were associated with injuries observed during the race.
\end{abstract}

Results.-Six hundred and twelve paddlers competed in the race, with 298 respondents participating in the study. Eighty-eight paddlers with a total of 135 injuries presented for medical assessment. More than one third of injuries involved the shoulder (35.6\%), followed by the thoracic spine (23\%), and lumbar spine (17\%). Men were 3.6 times (CI: 1.39 to $9.32, P=.01$ ) more likely to present with an injury compared with the women. A faster average speed (ie, faster finishing time) was correlated with a decrease in injury presentation (odds ratio 0.77 , CI: 0.63 to $0.93, P=.01$ ). Modifiable risk factors such as age, type of craft, paddling experience, HCC experience, training distances, and preceding injuries were not shown to increase the chance of injury presentation.

Conclusions.-Further data gathered over a series of this race may point to modifiable risk factors that may help reduce the incidence of injury.

Key words: injury, musculoskeletal, surveillance, canoe, kayak, paddling

\section{Introduction}

The Hawkesbury Canoe Classic (HCC) is a 111-km marathon paddling race (kayak and canoe) held annually in New South Wales, Australia. Paddling sports are a popular past time on many of Australia's rivers and oceans. The Australian Sports Commission annual report as to Australian sport and recreation participation estimated that 118800 Australians were involved in organized and nonorganized canoeing and kayaking during 2006. ${ }^{1}$ There were no available Australian data regarding injuries incurred with marathon canoeing and kayaking sports in general.

Corresponding author: David Abraham, Nepean Specialist Sports Medicine, 15/1A Barber Avenue, Kingswood, New South Wales 2747, Australia (e-mail: doomsie@netspace.net.au).
Kayak paddling is performed seated using a doublebladed paddle with a bilateral stroke. Canoe paddling can be performed seated or kneeling with a single-bladed paddle with a unilateral stroke. The paddling stroke consists of 3 components: the paddle enters the water (the catch), the body rotates and pulls the boat past the paddle entry point (power), before the blade exits the water (exit and recovery). ${ }^{2}$ Power is largely developed through rotation of the body rather than the use of the upper limbs.

There have been very few studies conducted on marathon paddling and risk factors for injury. A retrospective study into various paddling sports reported the majority of injuries involved the shoulder and back. ${ }^{3}$ The risk factors were not examined. Du Toit et $\mathrm{al}^{4}$ suggested that wrist tenosynovitis in long-distance canoeists was 
associated with difficult paddling conditions and with those who trained for more than $100 \mathrm{~km} /$ week in the 2 months preceding races. ${ }^{4}$

Impetus for this project was based on the Translating Research into Injury Prevention Practice framework, in particular stage 1 (injury surveillance) and stage 2 (understanding the etiology of why injuries occur). ${ }^{5} \mathrm{Com}-$ petitors in the HCC can be on the water for as long as 19 hours. Identifying risk factors may allow insight into modifiable risk factors that may reduce the chance of injury with marathon paddling. As there have been no prospective studies investigating musculoskeletal injuries or potential risk factors for injury in marathon paddling, the aim of this study was to identify musculoskeletal injuries sustained in the race and the risk factors associated with those injuries.

\section{Methods}

\section{THE HAWKESBURY CANOE CLASSIC}

The race is held overnight in late October and involves approximately 600 competitors in 250 water craft including single- and multiple-seat canoes and kayaks. Elite and not-elite competitors participate on a course that runs on the Hawkesbury River from Windsor in the northwest of Sydney to Brooklyn, to the north of Sydney. The 2006 HCC was the 30th running of the event.

\section{STUDY DESIGN AND PARTICIPANTS}

The research was conducted as a prospective observational cohort study on the 2006 HCC (October 24 and 25). The project was approved by the Hawkesbury Canoe Classic Association Committee as a Best Practice Quality Project, which complied with the National Health and Medical Research Council of Australia ethical guidelines. ${ }^{6}$

The 2006 HCC involved 612 competitors. Participation in the study was voluntary, with informed written consent obtained from each participant. A written preparticipation questionnaire was provided in the competitors' pre-race booklet and at registration before the commencement of the race to identify potential risk factors (Appendix): age, gender, type of water craft (canoe or kayak, single- or multiple-seat), paddling experience, HCC experience, familiarization paddles (number of practice paddles on the course with an experienced competitor), training history, and current injuries. A competitor's average speed $(\mathrm{km} / \mathrm{h})$ over the race was also calculated for analysis (finish times were not used because all competitors did not complete the race).
Injuries during and after the race were assessed and recorded by sports physicians and registrars from the Australasian College of Sports Physicians and experienced sports physiotherapists at each of 5 checkpoints and treatment areas along the course of the race. Competitors were identified by their boat number and initials, with the injured region, diagnosis, and management regimens recorded on a standardized injury collection sheet. An injury was defined as a musculoskeletal problem causing the patient pain or dysfunction or both that required assessment or treatment or both. Skin injuries such as lacerations, wounds, and blisters and hypothermia were not included, as the main focus of the study was identification of risk factors for musculoskeletal injuries only. Recurrent presentation of the same injury at more than 1 checkpoint was counted as a single injury.

\section{INJURY CLASSIFICATION}

All injuries were anatomically classified using the Orchard Sports Injury Classification System, Version 10 (OSICS-10) ${ }^{7}$ by the author (D.A.). This has been shown to be an effective and reliable classification system for musculoskeletal injuries. ${ }^{8,9}$

\section{DATA ANALYSIS}

Based on the available data for the 612 competitors, a Fisher's exact test was used to compare the tested subgroup (298 competitors) to the overall group (612 competitors) with the null hypothesis: there is no difference between the subgroup and the total group, based on gender. Continuous variables (age, HCC experience, paddling experience, speed) and categorical variables (gender, type of water craft [canoe/kayak], single/multiple-seat, familiarization, training history, current injury) were collated (Table 1). Data were entered into SPSS (version 17; SPSS Inc, Chicago, IL), and a backward stepwise logistic regression procedure with a likelihood ratio was used. Significant risk factors for injury were calculated using a standard probability value of $P<.05$. At each step, the variable with the highest nonsignificant value was omitted before further analysis. Odds ratios and $95 \% \mathrm{CI}$ were calculated.

\section{Results}

From the available race information, 500 men and 112 women competed in the race. Of the 612 competitors, 298 preparticipation questionnaires $(48.7 \%$ of competitors) were collected. A Fisher's exact test comparing the tested group ( $\mathrm{n}=298 ; 239$ men, 59 women) to the overall group ( $\mathrm{n}=612 ; 500$ men, 112 women) produced 
Table 1. Baseline characteristics of risk factors assessed for injury in the 2006 Hawkesbury Canoe Classic $(n=298)$

\begin{tabular}{|c|c|c|c|}
\hline Predictor variable (continuous) & & Mean $(S D)$ & Median $(95 \%$ CI $)$ \\
\hline Age, years & & $40.2(13.9)$ & $42.0(40.0-44.0)$ \\
\hline Race speed,km/h & & $8.4(1.7)$ & $8.3(8.1-8.5)$ \\
\hline Paddling experience, years & & $7.7(8.9)$ & $4.0(3.0-5.0)$ \\
\hline $\mathrm{HCC}$ experience, number competed & & $2.5(4.7)$ & $1.0(0.0-1.0)$ \\
\hline $\begin{array}{l}\text { Predictor variable } \\
\text { (categorical) }\end{array}$ & Total (\% of total) & $\begin{array}{l}\text { Number injured } \\
\text { (\% of total injured) }\end{array}$ & $\begin{array}{l}\text { Percent of predictor } \\
\text { variable injured }(\%)\end{array}$ \\
\hline \multicolumn{4}{|l|}{ Gender } \\
\hline Male & $239(80.2)$ & $57(90.4)$ & 23.8 \\
\hline Female & $59(19.8)$ & $6(9.6)$ & 10.2 \\
\hline Total & $298(100)$ & $63(100)$ & \\
\hline \multicolumn{4}{|l|}{ Type of water craft } \\
\hline Canoe & $23(7.7)$ & $1(1.6)$ & 4.3 \\
\hline Kayak & $275(92.3)$ & $62(98.4)$ & 22.5 \\
\hline Total & $298(100)$ & $63(100)$ & \\
\hline \multicolumn{4}{|l|}{ Number of seats } \\
\hline Single & $139(46.6)$ & $33(52.4)$ & 23.7 \\
\hline Multiple & $159(53.4)$ & $30(47.6)$ & 18.9 \\
\hline Total & $298(100)$ & $63(100)$ & \\
\hline \multicolumn{4}{|l|}{ Familiarization paddles } \\
\hline None & $203(68.1)$ & 39 (61.9) & 19.2 \\
\hline$\geq 1$ & 95 (31.9) & $24(38.1)$ & 25.3 \\
\hline Total & $298(100)$ & $63(100)$ & \\
\hline \multicolumn{4}{|l|}{ Training history } \\
\hline$<50 \mathrm{~km} / \mathrm{wk}$ & $199(66.8)$ & $49(77.8)$ & 24.6 \\
\hline$\geq 50 \mathrm{~km} / \mathrm{wk}$ & 99 (33.2) & $14(22.2)$ & 14.1 \\
\hline Total & $298(100)$ & $63(100)$ & \\
\hline \multicolumn{4}{|l|}{ Current injuries } \\
\hline No & $196(65.8)$ & $38(60.3)$ & 19.4 \\
\hline Yes & $102(34.2)$ & 25 (39.7) & 24.5 \\
\hline Total & $298(100)$ & $63(100)$ & \\
\hline
\end{tabular}

HCC, Hawkesbury Canoe Classic.

a 2 -tailed probability score of 0.59 , indicating that the sample group was a good representation of the group as a whole (thus accepting the null hypothesis of no difference between the 2 groups). The baseline characteristics of the cohort are displayed in Table 1.

\section{INJURY SURVEILLANCE}

Eighty-eight paddlers ( $14.4 \%$ of all competitors) presented for assessment and management of a musculoskeletal injury. The 88 injured paddlers were assessed to have had a total of 135 injuries (Table 2), with 39 paddlers (44.3\% of all injured paddlers) having 2 or more injuries. The injury rate for the entire group of 612 competitors was 20.5 injuries per 1000 hours of paddling. Shoulder, thoracic, and lumbar spines were the most commonly injured regions. Fifteen competitors with shoulder injuries ( $31.2 \%$ of shoulder injuries) had concurrent thoracic or lumbar spine injuries. Lower limb injuries represented only $3.7 \%$ of all injuries observed.

\section{RISK FACTORS}

Sixty-three $(71.5 \%)$ of the 88 paddlers had provided a preparticipation questionnaire. The 63 competitors represented $21.1 \%$ of the 298 competitors who submitted a preparticipation questionnaire, enabling an analysis of potential risk factors. The result (Table 3) produced the following model for injury: predicted $\log$ (injury) = $-0.97+-0.27$ (speed) +1.28 (male).

According to this model, the log of the odds for a competitor presenting with an injury was positively related to being male $(P<.05)$ and negatively related to speed $(P<.05)$. In other words, given the same speed, 
Table 2. Anatomical location of injuries during the 2006 Hawkesbury Canoe Classic

\begin{tabular}{llrr}
\hline \multicolumn{1}{c}{ Injured region } & OSICS-10 coding & Number & Percent \\
\hline Shoulder & SXXX & 48 & 35.6 \\
Thoracic spine & DXXX & 31 & 23.0 \\
Lumbar spine & LXXX & 23 & 17.0 \\
Forearm and wrist & RXXX, WXXX & 15 & 11.1 \\
Cervical spine & NXXX & 8 & 5.9 \\
Arm and elbow & UXXX, EXXX & 5 & 3.7 \\
Lower limb & GXXX & 5 & 3.7 \\
Totals & & 135 & 100 \\
\end{tabular}

OSICS-10, Orchard Sports Injury Classification System, Version 10.

the odds of a male presenting with an injury were 3.60 times that of the odds for a female. Similarly, controlling for gender, the higher the speed (that is, a quicker finish time), the less likely it was that a competitor would present with an injury. For example, the odds of a competitor completing the race in 15 hours $(7.4 \mathrm{~km} / \mathrm{h})$ presenting with an injury was 2.6 times more $\left(\mathrm{e}^{-0.27 \times 7.4} / \mathrm{e}^{-0.27 \times 11}\right)$ compared with a competitor finishing in 10 hours $(11 \mathrm{~km} / \mathrm{h})$.
Age, type of water craft (canoe or kayak, single- and multiple-seat), paddling experience, HCC experience, familiarization paddles, training distance, and a preceding injury were not predictive of injury.

\section{Discussion}

This study indicates that the majority of musculoskeletal injuries affected the shoulder region and back (thoracic and lumbar). This finding is in keeping with a prior retrospective study by Kameyama et $\mathrm{al},{ }^{3}$ who reported that the upper limb and back regions formed 35\% and $22 \%$ of paddling injuries, respectively. Carmont et al, ${ }^{10}$ in a retrospective questionnaire, reported injuries affecting the wrist (21\%), shoulder (19\%), and back (14\%) in kayakers in the 2004 Devizes to Westminster Canoe and Kayak Marathon. A recent survey by Haley and Nich$\mathrm{ols}^{11}$ on outrigger canoeists in Hawaii confirms findings similar to those of this study, with shoulders (40\%), back (26\%), and hand/wrists (10\%) forming the majority of musculoskeletal injuries incurred with a paddling sport.

We did not investigate the cause of the competitors' shoulder or spine injuries. However, it is important to

Table 3. Logistic regression analysis of 298 competitors for risk factors associated with sustaining a musculoskeletal injury in the 2006 Hawkesbury Canoe Classic

\begin{tabular}{|c|c|c|c|c|}
\hline Predictor variable & $\beta$ & Wald $\chi^{2}$ & Odds ratio $(95 \% \mathrm{CI})$ & $P$ value \\
\hline Age & -0.02 & 2.95 & $0.98(0.96-1.00)$ & .09 \\
\hline Paddling experience & -0.01 & 0.05 & $0.99(0.96-1.04)$ & .82 \\
\hline HCC experience & 0.01 & 0.02 & $1.01(0.92-1.10)$ & .90 \\
\hline Speed & -0.27 & 6.99 & $0.77(0.63-0.93)$ & $.01^{a}$ \\
\hline \multicolumn{5}{|l|}{ Gender } \\
\hline Female (reference) & $\ldots$ & $\ldots$ & $\ldots$ & $\ldots$ \\
\hline Male & 1.28 & 6.97 & $3.60(1.39-9.32)$ & $.01^{a}$ \\
\hline \multicolumn{5}{|l|}{ Water craft } \\
\hline Canoe (reference) & $\ldots$ & $\ldots$ & $\ldots$ & $\ldots$ \\
\hline Kayak & 1.56 & 2.18 & $4.75(0.60-37.67)$ & .14 \\
\hline \multicolumn{5}{|l|}{ Number of seats } \\
\hline Single (reference) & $\ldots$ & $\ldots$ & $\ldots$ & $\ldots$ \\
\hline Multiple & -0.30 & 0.84 & $0.74(0.39-1.40)$ & .36 \\
\hline \multicolumn{5}{|l|}{ Familiarization paddles } \\
\hline None (reference) & $\ldots$ & $\ldots$ & $\ldots$ & $\ldots$ \\
\hline$\geq 1$ & 0.45 & 2.08 & $1.57(0.85-2.91)$ & .15 \\
\hline \multicolumn{5}{|c|}{ Training distance (per week) } \\
\hline$<50$ km (reference) & $\ldots$ & $\ldots$ & $\ldots$ & $\ldots$ \\
\hline$\geq 50 \mathrm{~km}$ & -0.20 & 0.28 & $0.82(0.39-1.73)$ & .16 \\
\hline \multicolumn{5}{|l|}{ Preceding injury } \\
\hline No (reference) & $\ldots$ & $\ldots$ & $\ldots$ & $\ldots$ \\
\hline Yes & 0.45 & 2.12 & $1.57(0.86-2.90)$ & .15 \\
\hline Constant & -0.97 & 0.56 & $\ldots$ & $\ldots$ \\
\hline
\end{tabular}

HCC, Hawkesbury Canoe Classic.

${ }^{a}$ Significant. 
recognize the pathology behind such injuries. Studies by Hagemann et $\mathrm{al}^{12}$ and Kameyama et $\mathrm{al}^{3}$ included investigations to determine the most common pathologies in each of these areas associated with paddling. As noted earlier, nearly one third of competitors with a shoulder injury had concurrent thoracic or lumbar spine complaints. Similar findings were noted in the study by Kameyama et $\mathrm{al}^{3}$ in which $25 \%$ of 417 respondents complained of concurrent shoulder and low back pain. Those researchers performed diagnostic investigations on competitive canoeists and noted that $52.3 \%$ of 63 competitive canoeists complained of low back problems. ${ }^{3}$ The pathology included spondylolysis (17.5\%), myofascial pain (15.9\%), spondylosis deformans (12.7\%), and disc herniation $(3.2 \%){ }^{3}$

Hagemann et al $^{12}$ investigated marathon kayakers' shoulders and found that 22 of 52 marathon kayakers had symptoms of shoulder pain or instability. Of the 52 shoulders scanned with magnetic resonance imaging, 27 (52\%) demonstrated pathology, with acromioclavicular joint hypertrophy (55\%), acromial spurs (40\%), and rotator cuff pathology (44\%) being the most common. The kayaker's age, paddling experience, and number of endurance events did not correlate with symptoms or magnetic resonance imaging findings. That is similar to the finding of this study of no correlation between age, injury, and paddling or HCC experience.

This study showed that a slower average speed (that is, a slower finishing time) was correlated with an increased risk of injury. There are two possible explanations for this finding. First, competitors who have less proficient paddling and have poor techniques and biomechanics would be more likely to be prone to muscle fatigue and, hence, injury. The overuse shoulder injury is thought to be due to alterations of scapular kinematics, in particular, reduced serratus anterior activity reducing upward scapular rotation, and excessively increased upper trapezius activity increasing clavicular and scapular elevation. ${ }^{13}$ Biomechanical issues such as thoracic kyphosis (flexed posture) causing reduced upward scapular rotation, muscle fatigue, and altered shoulder girdle muscle activation patterns may contribute to shoulder impingement syndromes and glenohumeral joint instability through altered scapulothoracic mechanics. ${ }^{13}$ Second, competitors incurring injuries during the race would most likely need to slow their paddling pace, therefore recording a slower time. It is a limitation of observational studies that cause and effect relationships are difficult to determine owing to the inability to randomize subjects. Indeed, there may be confounding variables not studied in this race that may contribute to the association between race speed and injury status.
Men were noted to have higher injury rates than women. This result is consistent with the 2005 NSW Injury Surveillance Report, ${ }^{14}$ which found that men in all sports, at all ages, were more likely to have sport-related hospitalizations than were women. Findings of men presenting 3.5 times more often than women are very similar to the results of this study. Men typically have higher participation rates in all sports, and that may partly account for their higher injury presentation rates. ${ }^{1}$

The HCC had an overall injury presentation rate of $14.4 \%$. Although that might seem to be a high injury presentation rate (approximately 1 in 7 competitors), it is likely that this is an underestimation of the true injury incidence for this event. ${ }^{14}$ A PubMed and MEDLINE database search for injury surveillance data for comparable single sport endurance events such as the marathon, endurance cycling events, and open water swimming revealed a paucity of articles regarding injury surveillance. Nicholl et al ${ }^{15}$ studied the 1982 Sheffield Marathon and reported $18 \%$ of 2289 competitors presented with 1 or more injuries. That is not dissimilar to the findings of this study. Satterthwaite et $\mathrm{al}^{16}$ reported that $6.2 \%$ of competitors in the Auckland Marathon presented with an injury on the day of the event; however, $92.4 \%$ of competitors reported a specific problem in the days immediately after the event.

\section{STUDY LIMITATIONS}

While the final logit model achieved adequate power for the included predictor variables (gender and speed), it could be argued that other predictor variables (such as age, inexperience with paddling, prior injury, familiarization paddles, training history, and type of water craft) may have been predictive of injury if not for the smaller sample size, $\mathrm{n}=298$, and reduced power. Competitors who did not present for assessment may have indeed had injuries that may have been more evident in the days after the race. Post-race contact with competitors (by e-mail or Internet survey) could have assisted in collecting further data. This issue was broached with the HCC organizing committee, but they considered that such contact may have breached privacy concerns.

Participation of all competitors in the research may have allowed a detection of significant modifiable risk factors between the injured and noninjured. The results of this study are likely an underestimation of the true incidence of injuries occurring with marathon paddling. This limitation in injury surveillance is acknowledged in the 2005 NSW Injury Surveillance Report, ${ }^{14}$ indicating that nearly $50 \%$ of people involved in organized and nonorganized sports have self-treated injuries. That limits the ability of researchers to build adequate injury 
databases. Further study into injuries associated with marathon paddling in the HCC may include encouragement of all competitors to complete preparticipation questionnaires and present for medical assessment at the conclusion of their race. Logistically, that would require a much larger medical team, and may prove difficult.

A self-selection bias may have also existed. Competitors who completed the preparticipation questionnaire may have had a vested interest in the outcome, hence presenting for injury assessments. That may account for the discrepancy of $21.1 \%$ of the cohort presenting for review of injury compared with $14.4 \%$ of all competitors.

A longitudinal study over a number of races may provide more data for risk assessment as other factors may play a role in sustaining musculoskeletal injuries. Factors such as technique, fitness, clothing, weather conditions (temperature, wind), water conditions (tide, choppiness of water), and equipment issues (water craft, paddle type) may need to be evaluated. As with the study by Hagemann et al, ${ }^{12}$ shoulder injuries may be related to nonmodifiable anatomical factors such as acromioclavicular spurs causing impingement syndromes and rotator cuff pathology.

\section{Conclusions}

Shoulder and spine injuries were the most common finding within this cohort of marathon paddlers. That would be consistent with the repetitive nature of paddling involving shoulder and spine rotation over long periods of time. Being male and having low paddling speed were identified as risk factors for injuries, but preparticipation modifiable risk factors were not identified. Further study into marathon paddling-related musculoskeletal injuries is needed to identify specific risk factors that will allow preventive measures to be instituted.

\section{Acknowledgments}

The authors would like to thank the Hawkesbury Canoe Classic Association and all support staff for their cooperation and participation in this project. Special thanks to the sports physiotherapists, and to Drs Corey Cunningham, Karen Soo, and Brendan O'Neill for assisting with the injury assessments.

\section{References}

1. Standing Committee on Recreation and Sport. Participation in exercise, recreation and sport: annual report 2006. Canberra, Australian Capital Territory: Standing Commit- tee on Recreation and Sport, Australian Sports Commission, Dept Communications, Information Technology and the Arts; 2007.

2. Carter P. Paddle your own. Available at: http:// www.canoe.org.au/site/canoeing/ac/downloads/education/ acas/resources/techniques/paddle_your_own.pdf. Accessed January 25, 2011.

3. Kameyama O, Shibano K, Kawakita H, Ogawa R, Kumamoto M. Medical check of competitive canoeists. J Orthop Sci. 1999;4:243-249.

4. Du Toit P, Sole G, Bowerbank P, Noakes TD. Incidence and causes of tenosynovitis of the wrist extensors in long distance paddle canoeists. Br J Sports Med. 1999;33: 105-109.

5. Finch C. A new framework for research leading to sports injury prevention. J Sci Med Sport. 2006;9:3-10.

6. National Health and Medical Research Council ARC. National statement on ethical conduct in research involving humans (1999). Available at: http://www.nhmrc.gov.au/ publications/synopses/e35syn.htm. Accessed May 17, 2006.

7. Orchard J. Orchard Sports Injury Classification System (OSICS). Available at: http://www.injuryupdate.com.au/ research/OSICS.htm. Accessed June 20, 2007.

8. Rae K, Britt H, Orchard J, Finch C. Classifying sports medicine diagnoses: a comparison of the International Classification of Diseases 10-Australian Modification (ICD-10-AM) and the Orchard Sports Injury Classification System (OSICS-8). Br J Sports Med. 2005;39: 907-911.

9. Rae K, Orchard J. The Orchard Sports Injury Classification System (OSICS) Version 10. Clin J Sport Med. 2007;17: 201-204.

10. Carmont MR, Baruch MR, Burnett C, Cairns P, Harrison JWK. Injuries sustained during marathon kayak competition: the Devizes to Westminster race. $\mathrm{Br} J$ Sports Med. 2004;38:650-653 [abstract 001].

11. Haley A, Nichols A. A survey of injuries and medical conditions affecting competitive adult outrigger canoe paddlers on O'ahu. Hawaii Med J. 2009;68:162-165.

12. Hagemann G, Rijke AM, Mars M. Shoulder pathoanatomy in marathon kayakers. Br J Sports Med. 2004;38:413-417.

13. Ludewig PM, Reynolds JF. The association of scapular kinematics and glenohumeral joint pathologies. J Orthop Sports Phys Ther. 2009;39:90-104.

14. Mitchell R, Boufous S, Finch CF. Sport/leisure injuries in New South Wales: trends in sport/leisure injury hospitalizations (2003-2005) and the prevalence of non-hospitalised injuries (2005). Sydney, Australia: New South Wales Injury Risk Management Research Centre; 2008.

15. Nicholl JP, Williams BT. Injuries sustained by runners during a popular marathon. Br J Sports Med. 1983;17: $10-15$.

16. Satterthwaite P, Larmer P, Gardiner J, Norton R. Incidence of injuries and other health problems in the Auckland Citibank marathon, 1993. Br J Sports Med. 1996;30: $324-326$. 
Appendix

Hawkesbury Canoe Classic questionnaire.

Race Number :

Initials

Sex $\quad:$ MALE FEMALE

Age

Craft

Number of years paddling:

Number of previous HCCs competed in:

Have you participated in any familiarisation paddles this year? YES NO If $\underline{\text { YES}}$, how many?

In the last 8 weeks (2 months), what was your average training distance PER WEEK? $0-50 \mathrm{~km} \quad 51-100 \mathrm{~km}$

Do you have any current injuries? YES NO If $\underline{\text { YES}}$, please circle the affected region:

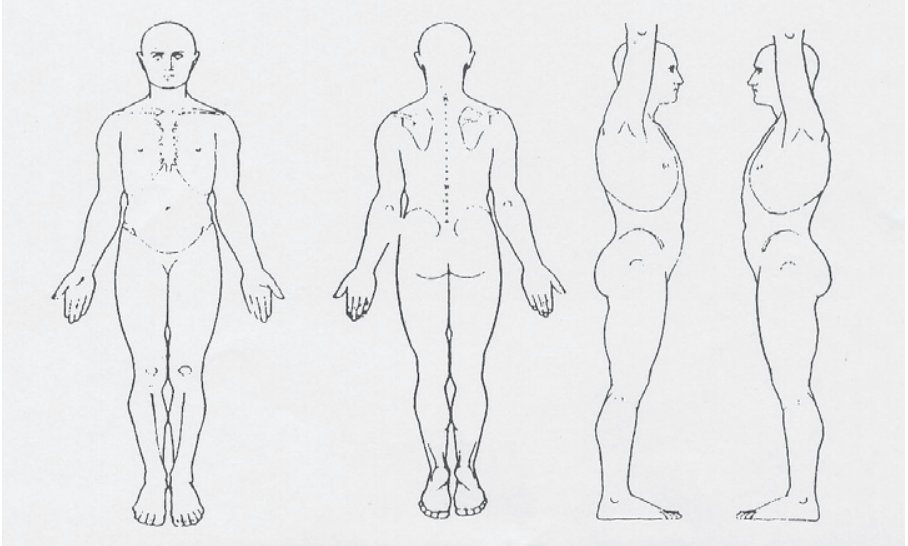

Signature of participant 